\title{
Primary Urethral Malignant Melanoma in an Elder Woman Diagnosed by Urine Cytology
}

\author{
Kenji Niwa ${ }^{1 *}$, Tsuneo Ishihara ${ }^{1}$, Sakae Mori², Keigo Kuwabara' ${ }^{2}$, Saki Murase ${ }^{3}$, \\ Motoki Takenaka ${ }^{3}$, Yoshio Yamaguchi², Takuji Tanaka ${ }^{4}$ (i) \\ ${ }^{1}$ Department of Obstetrics \& Gynecology, Gujo City Hospital, Gujo, Japan \\ ${ }^{2}$ Section of Laboratory Medicine, Gujo City Hospital, Gujo, Japan \\ ${ }^{3}$ Department of Obstetrics \& Gynecology, Gifu University School of Medicine, Gifu, Japan \\ ${ }^{4}$ Department of Diagnostic Pathology \& Research, Center of Diagnostic Pathology, Gifu Municipal Hospital, Gifu, Japan \\ Email: ^kniwa.gujo913@gmail.com
}

How to cite this paper: Niwa, K., Ishihara, T., Mori, S., Kuwabara, K., Murase, S., Takenaka, M., Yamaguchi, Y. and Tanaka, T. (2020) Primary Urethral Malignant Melanoma in an Elder Woman Diagnosed by Urine Cytology. Open Journal of Pathology, 10, 16-23. https://doi.org/10.4236/ojpathology.2020.101 002

Received: November 1, 2019

Accepted: December 28, 2019

Published: December 31, 2019

Copyright (c) 2020 by author(s) and Scientific Research Publishing Inc. This work is licensed under the Creative Commons Attribution International License (CC BY 4.0).

http://creativecommons.org/licenses/by/4.0/

\begin{abstract}
Primary urethral malignant melanoma is an extremely rare malignancy with early metastasis and often delayed diagnosis, resulted in poor prognosis. Literature on this entity, especially with regard to urinary cytology is limited. We report here an extremely rare case of primary urethral malignant melanoma (MM) developed in a 95-year-old Japanese woman. A urinalysis showed macrophages containing brown granular pigments, and the urinary cytology was positive for atypical cells containing brown pigments suggestive of MM. Pathological examination of the biopsy specimen from the tumor revealed MM of the urethra. Immunohistochemically, the tumor cells showed strong cytoplasmic reactivities against antibodies, HMB- 45 and Malan-A. Melanoma cells were immunohistochemically positive for c-Kit in their cytoplasm and cell membrane, although mutations in $B R A F \mathrm{~V} 600 \mathrm{E}$ and $N / K-R A S$ were not detected. The urinary cytology and immunohistochemistry were useful for the rapid and accurate diagnosis for the urethral MM.
\end{abstract}

\section{Keywords}

Malignant Melanoma, Urethra, Cytology, Immunohistochemistry, HMB-45, Melan-A, c-KIT

\section{Introduction}

Malignant melanomas (MMs) are divided into two sub-types: chronically sun damaged (CSD) skin, which occurs to the sunlight exposure part and non-CSD types, including acral and mucosal melanomas by genetic mutations [1] [2] [3]. Primary urethral MM belongs to mucosal melanoma and has poor prognosis [4]. 
Primary MM of the genitourinary tract is rare, accounting for less than $1 \%$ of all cases of MM [5] [6]. Primary urethral MM predominantly occurs in females and represents only $0.2 \%$ of all MM [7]: the ratio of males:females being 3:1 with an average of presentation age being 65 years, ranging from 29 to 96 years of age [8] [9] [10]. Most female urethral MMs are located at the meatus and/or in the distal urethra [11]. The common clinical presentations include bleeding, discharge, voiding dysfunction and the presence of the tumor [12]. Up to date, cytological findings of MM of the female urethra have scarcely been reported [13] [14] [15]. In the present report, we present an extremely rare case of MM originating from the urethra in a 95-year-old Japanese woman, which was rapidly diagnosed by urinary cytology and confirmed by HMB-45- and Melan-A-immunohistochemistry.

\section{Case Report}

A 95-year-old female, gravida four para four, presented to our hospital with intermittent vaginal spotting for several weeks. She had no history of urogenital symptoms or diseases, although she had hypertension. On physical examination, there was a mass protruding from the urethral meatus. It was $28 \times 15 \mathrm{~mm}$ in diameter, tan colored and hemorrhagic (Figure 1). A urinalysis showed macrophages containing brown granular pigments (Figure 2(a)), and the urinary cytology showed

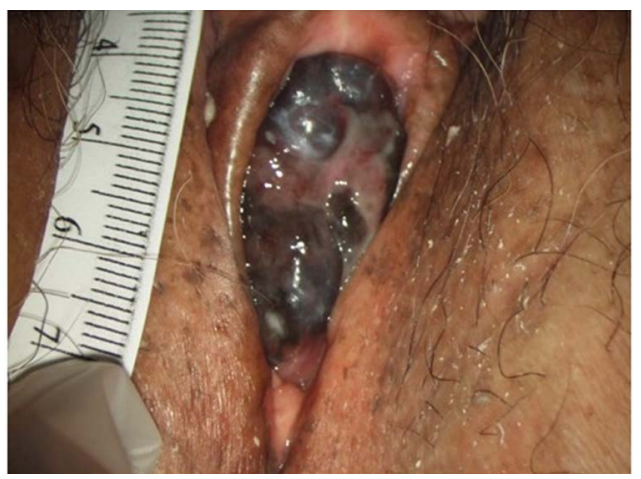

Figure 1. A tan colored tumor with hemorrhage, measuring $28 \times 15 \mathrm{~mm}$, which projects from the urethra inside is observed.
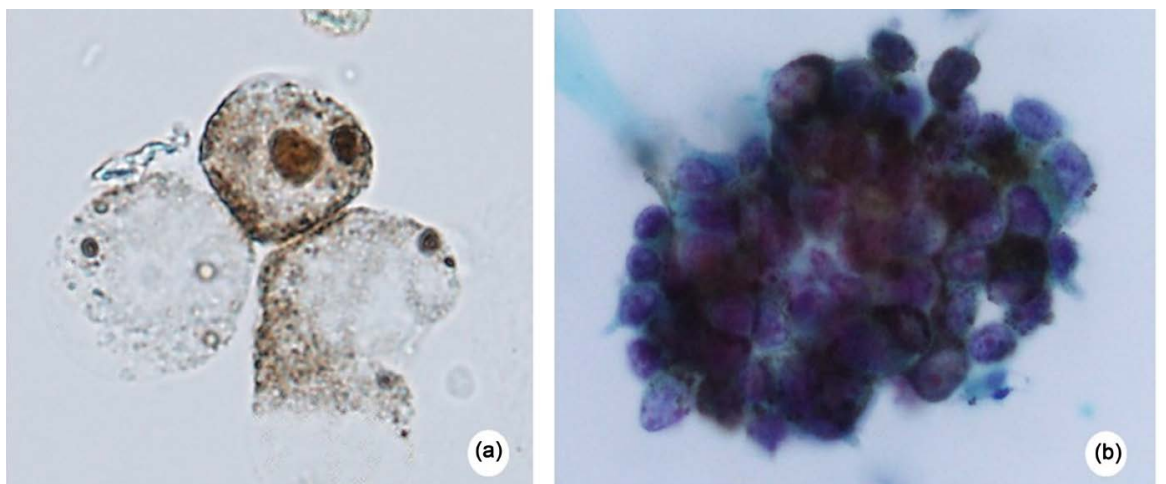

Figure 2. (a) Urinalysis showing macropharges containing brown granular pigments suggesting melanopharges $(\times 800)$. (b) Aypical cells with brown pigments in their cytoplasm are noted in the urine cytology, suggesting malignant melanoma (Ppanicolaou stain, $\times 400$ ). 
atypical cells containing brown pigments suggestive of MM (Figure 2(b)). Biopsy specimen for pathological diagnosis was obtained from the urethral tumor at her first visit. The specimen was fixed in $10 \%$ neutral buffered formalin, routinely processed, and embedded in paraffin for histological and immunohistochemical examinations. Step sections with $3-4 \mu \mathrm{m}$ thickness were made and stained with hematoxylin and eosin ( $\mathrm{H} \& \mathrm{E})$ for histopathological diagnosis. In addition, immunohistochemistry using three different antibodies, such as HMB-45 (monoclonal mouse anti-human melanosome, clone HMB-45, 1:30 dilution, DAKO), Melan-A (mouse monoclonal clone M2-7C10, 1:10 dilution, Nichirei), and c-Kit (rabbit polyclonal, 1:400 dilution, DAKO) was performed. Histopathological examination revealed MM of the urethra (Figure 3(a) and Figure 3(b)). Immunohistochemically, the tumor cells showed strong cytoplasmic reactivities for HMB-45 and Malan-A (Figure 3(c) and Figure 3(d)). Their cytoplasm and cell membrane were positive for c-Kit (Figure 3(e)). The blood examinations including lactate dehydrogenase (177 IU/l), neuron-specific enolase $(11.0 \mathrm{ng} / \mathrm{ml})$ and a-fetoprotein $(3.1 \mathrm{ng} / \mathrm{ml})$ were within normal limits. The tumor was suspected to invade to the anterior vaginal wall on magnetic resonance imaging (MRI) (Figure 4), but the whole body CT showed no metastases. Although unstained tumor tissue sections (10 $\mu \mathrm{m}$ thick) were used for examining mutations in $N / K$-RAS (codon 12 , $13,59,61,117,146)$ and $B R A F$ V600E genes by the PCR-rSSO method, we did not detect the mutations. The patient and her family did not wish further therapies, when considering her age. She received a herbal medicine, "Juzen-taiho-to" and a Lactobacillus casei medicine, "Biolactis powder", which was reported to have
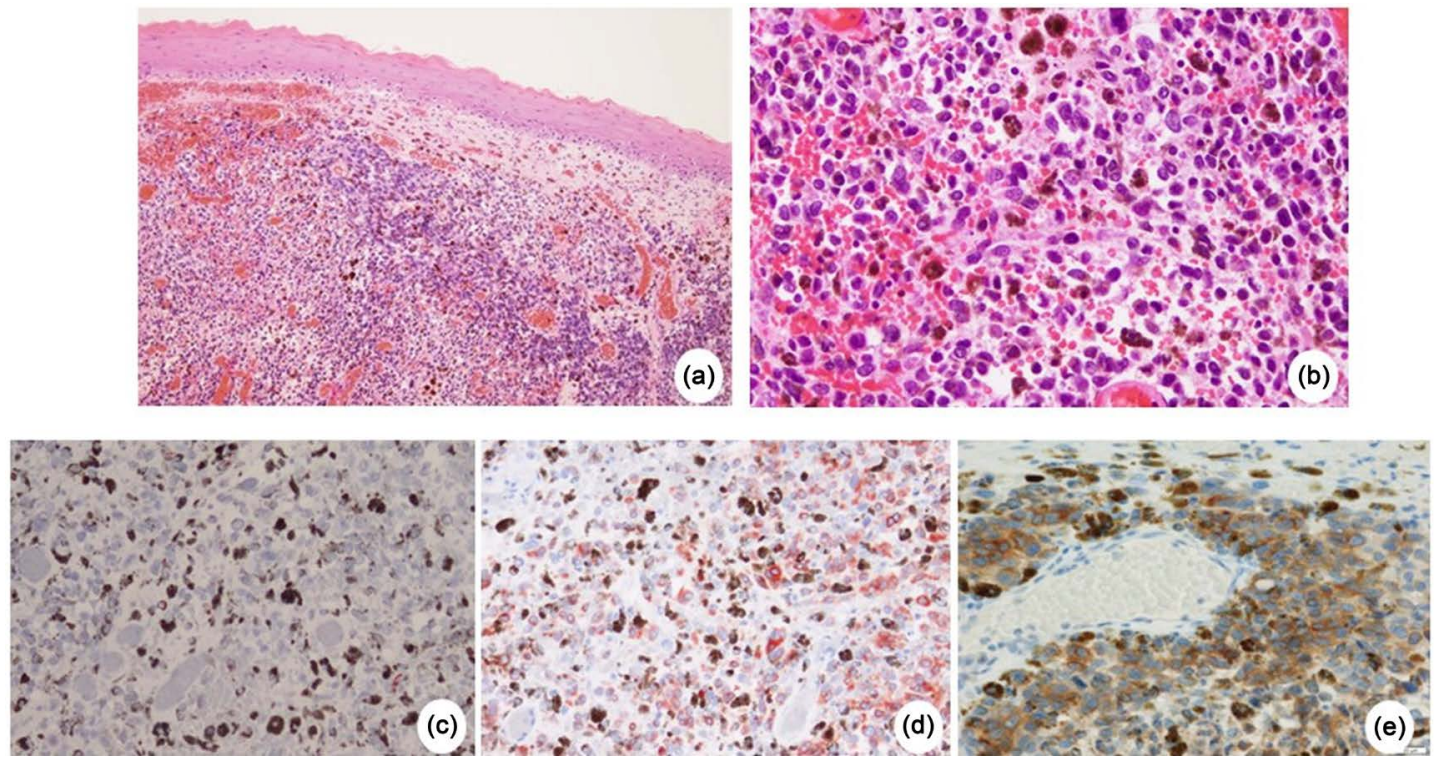

Figure 3. Histolpathology of the urethral tumor. (a) Pigmented tumor cells proliferate and infiltrate under the urethral epithelium, suggesting malignant melanoma. (b) High magnification of melanoma cells containing melanin granules in their cytoplasm. Tumor cells are immunohistchemically positive for (c) HMB-45 and (d) Melan-A. (e) Cytoplasm and cell membrane were immunohistochemically reacted with c-Kit antibody. (a) H \& E stain, $\times 40$; (b) H \& E stain, $\times 400$; (c) HMB-45 immunohistochemistry, $\times 400$; (d) Melan-A immunohistochemistry, $\times 400$; and (e) c-Kit immunohistochemisty, bar $=20 \mu \mathrm{m}$. 

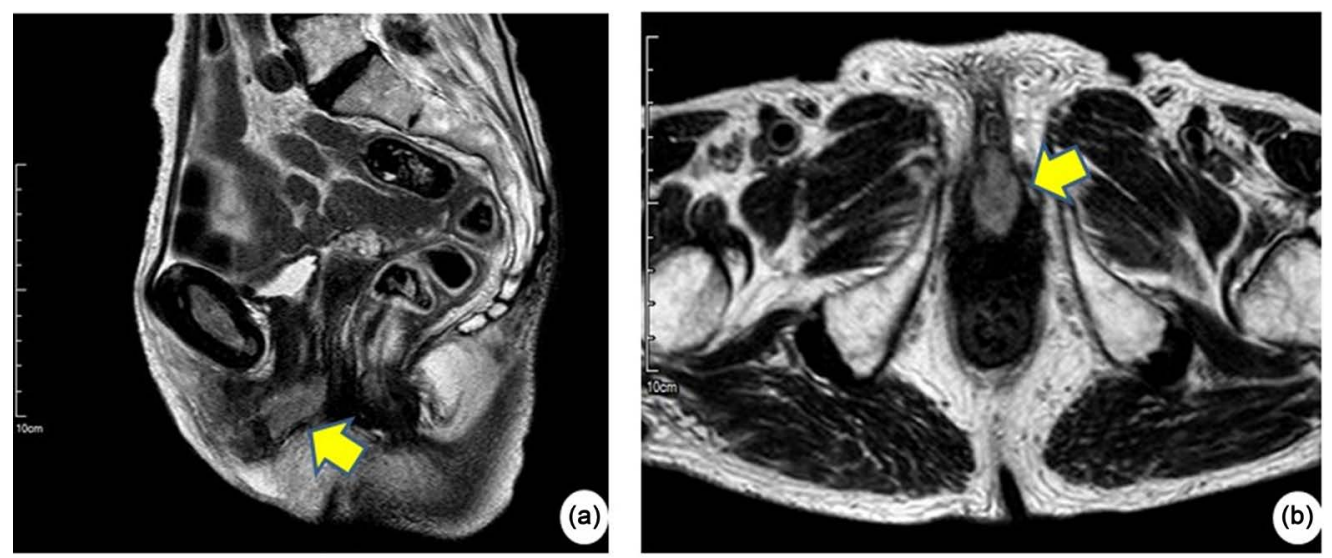

Figure 4. T1-weighted MRI examination ((a) and (b)) shows the urethral tumor, located at the urethral distal end (arrows).

prophylactic effect on recurrence of bladder cancer [16]. Although surgical resection of the tumor was not performed in this case, staging grouping of this tumor was considered to be Stage III (T3aN0M0). Nine months after the first visit, the patient was alive with an intermittent vaginal spotting and the tumor did not grow-up.

\section{Discussion}

It is considered that primary MMs of the genitourinary tract arise from ectopic melanocytes which arrest in the urothelium during the embryonic migration from the neural crest [17]. To date, there are a few systematic reviews on this malignancy in English literature: 150 cases [9] and 36 cases [18]. The most frequent presentation was urethral mass the meatus [9] [18], as presented in the present case. Although the first line of treatment was surgery (tumor excision or total urethrectomy) [9] [18], our patient did not agree with surgical resection of the tumor. Primary urethral MM is three times more common in women than men and tends to occur in old patients, averaging 65 years [8] [9] [10]. The female predominance might be a higher concentration of melanocytes in the mucocutaneous tissue of the vulva [19]. Most MMs of the female urethra are located at the meatus and/or in the distal urethra [11], as shown in this case. The age (95-year-old) of our case is one of the highest in the English literature [8] [9] [10].

The urethral MMs may be easily confused with caruncle [20], and are frequently misdiagnosed clinically, which leads to delayed diagnosis [21]. Thus, patients with the urethral MMs usually show a poor prognosis [21]. Primary MM of the female urethra tends to metastasize at early stage via the superficial lymphatics to the vulva and vagina to the inguinal lymph nodes by the deep lymphatics and occasionally to distal sites by the haematogenous route [22]. The urinalysis of the present case showed melanophages, and the urinary cytology was positive for melanoma cells at the first visit. On the same day, pathological diagnosis on the biopsy specimen obtained from the urethral tumor revealed the 
MM. As we experienced [14], immunohistochemical examination using most frequently utilized melanocytic markers, HMB-45 and Melan-A, was useful for the accurate diagnosis of MMs. The monoclonal antibody, HMB-45, is quite specific melanocytic neoplasms, and Melan-A also reacts with more than $75 \%$ of melanomas [23] [24] [25]. In the present case, strong immunoreactivity against HMB-45 and Melan-A was found and the findings were useful for the diagnosis of the urethral MM, leading the early and accurate diagnosis. The patient had no metastases at the diagnosis, although she did not wish further therapies for this malignancy.

MRI can be used for diagnosis of urethral MM and evaluation of the tumor extent [26] [27]. Melanin may not follow the same MRI intensity pattern as other urethral tumors, since its appearance may depend on the intralesional melanin content [27]. In the present case, the intralesional melanin content was relatively rich, thus the lesion was recognized at the urethral meatus on the T1 high intensity.

Melanoma developed in the female urogenital region is a rare neoplasm with poor prognosis [28]. While $B R A F \mathrm{~V} 600 \mathrm{E}$ is known to be the most common pathogenic mutation found in melanoma in the sun-exposed skin, mucosal and genitourinary melanomas usually lack mutations in $B R A F \mathrm{~V} 600 \mathrm{E}$, but harbor c-KIT mutations [28]. As to $N$-RAS, melanomas of the female urogenital tract, mutations in $N-R A S$ are relatively common [29]. In this case, we did not found mutations of $B R A F \mathrm{~V} 600 \mathrm{E}$ and $N / K-R A S$ in the tumor. However, immunohistochemical expression of c-Kit was noticed in the cytoplasm and cell membrane of melanoma cells, suggesting that targeted therapy against $C$-KIT activating mutations may be promising treatment [30] [31].

\section{Conclusion}

We report here an extremely rare case of primary malignant urethral melanoma developed in a 95-year-old Japanese woman. Urinalysis and urinary cytology were useful for our final diagnosis, urethral MM. Immunohistochemically, the tumor cells showed strong cytoplasmic reactivities for HMB-45 and Malan-A. The urinary cytology and immunohistochemistry for HMB-45 and Malan-A were useful for the early and accurate diagnosis for the urethral MM.

\section{Acknowledgements}

We thank the editor and reviewers for the constructive comments, which helped us to improve the manuscript. This case report was approved by the patient verbal consent.

\section{Conflicts of Interest}

The authors declare no conflicts of interest regarding the publication of this paper.

\section{References}

[1] Bastian, B.C., Olshen, A.B., LeBoit, P.E. and Pinkel, D. (2003) Classifying Melano- 
cytic Tumors Based on DNA Copy Number Changes. The American Journal of Pathology, 163, 1765-1770. https://doi.org/10.1016/S0002-9440(10)63536-5

[2] Curtin, J.A., Busam, K., Pinkel, D. and Bastian, B.C. (2006) Somatic Activation of KIT in Distinct Subtypes of Melanoma. Journal of Clinical Oncology, 24, 4340-4346. https://doi.org/10.1200/JCO.2006.06.2984

[3] Curtin, J.A., Fridlyand, J., Kageshita, T., Patel, H.N., Busam, K.J., Kutzner, H., Cho, K.H., Aiba, S., Brocker, E.B., LeBoit, P.E., Pinkel, D. and Bastian, B.C. (2005) Distinct Sets of Genetic Alterations in Melanoma. The New England Journal of Medicine, 353, 2135-2147. https://doi.org/10.1056/NEJMoa050092

[4] Papes, D. and Altarac, S. (2013) Melanoma of the Female Urethra. Medical Oncology, 30, 329. https://doi.org/10.1007/s12032-012-0329-2

[5] Das, P., Kumar, N., Ahuja, A., Jain, A., Ray, R., Sarkar, C. and Gupta, S.D. (2010) Primary Malignant Melanoma at Unusual Sites: An Institutional Experience with Review of Literature. Melanoma Research, 20, 233-239. https://doi.org/10.1097/CMR.0b013e328334c39a

[6] Gupta, R., Bhatti, S.S., Dinda, A.K. and Singh, M.K. (2007) Primary Melanoma of the Urethra: A Rare Neoplasm of the Urinary Tract. International Urology and Nephrology, 39, 833-836. https://doi.org/10.1007/s11255-006-9086-5

[7] Akbas, A., Akman, T., Erdem, M.R., Antar, B., Kilicarslan, I. and Onol, S.Y. (2010) Female Urethral Malignant Melanoma with Vesical Invasion: A Case Report. The Kaohsiung Journal of Medical Sciences, 26, 96-98. https://doi.org/10.1016/S1607-551X(10)70014-0

[8] DiMarco, D.S., DiMarco, C.S., Zincke, H., Webb, M.J., Keeney, G.L., Bass, S. and Lightner, D.J. (2004) Outcome of Surgical Treatment for Primary Malignant Melanoma of the Female Urethra. The Journal of Urology, 171, 765-767. https://doi.org/10.1097/01.ju.0000104671.20863.47

[9] El-Safadi, S., Estel, R., Mayser, P. and Muenstedt, K. (2014) Primary Malignant Melanoma of the Urethra: A Systematic Analysis of the Current Literature. Archives of Gynecology and Obstetrics, 289, 935-943. https://doi.org/10.1007/s00404-013-3130-3

[10] Oliva, E., Quinn, T.R., Amin, M.B., Eble, J.N., Epstein, J.I., Srigley, J.R. and Young, R.H. (2000) Primary Malignant Melanoma of the Urethra: A Clinicopathologic Analysis of 15 Cases. The American Journal of Surgical Pathology, 24, 785-796. https://doi.org/10.1097/00000478-200006000-00003

[11] Kim, C.J., Pak, K., Hamaguchi, A., Ishida, A., Arai, Y., Konishi, T., Okada, Y. and Tomoyoshi, T. (1993) Primary Malignant Melanoma of the Female Urethra. Cancer, 71, 448-451.

https://doi.org/10.1002/1097-0142(19930115)71:2<448::AID-CNCR2820710227>3.0 .CO;2-Y

[12] Filipkowski, L.A., Barker, M.A. and Karram, M.M. (2009) Primary Genitourinary Melanoma Presenting as Voiding Dysfunction. International Urogynecology Journal and Pelvic Floor Dysfunction, 20, 1141-1143. https://doi.org/10.1007/s00192-009-0817-x

[13] DeSimone, R.A. and Hoda, R.S. (2015) Primary Malignant Melanoma of the Urethra Detected by Urine Cytology in a Male Patient. Diagnostic Cytopathology, 43, 680-682. https://doi.org/10.1002/dc.23258

[14] Kawaguchi, N., Nambu, K., Sekiya, A., Sakakima, T., Matsuyama, M., Etori, F., Komeda, H., Hirai, K., Watanabe, N., Naiki, T., Yamada, T. and Tanaka, T. (2014) Primary Malignant Melanoma of the Female Urethra: A Rare Case of Cytological 
Observation. Pathology Discovery, 2, 5. https://doi.org/10.7243/2052-7896-2-5

[15] Pillai, K.R., Kumari, A., Augustine, J., Amma, N.S. and Nair, M.K. (1995) Cytodiagnosis of Primary Malignant Melanoma of the Female Urethra-A Case Report. Indian Journal of Pathology and Microbiology, 38, 103-108.

[16] Naito, S., Koga, H., Yamaguchi, A., Fujimoto, N., Hasui, Y., Kuramoto, H., Iguchi, A. and Kinukawa, N. (2008) Prevention of Recurrence with Epirubicin and Lactobacillus casei after Transurethral Resection of Bladder Cancer. The Journal of Urology, 179, 485-490. https://doi.org/10.1016/j.juro.2007.09.031

[17] Khalbuss, W.E., Hossain, M. and Elhosseiny, A. (2001) Primary Malignant Melanoma of the Urinary Bladder Diagnosed by Urine Cytology: A Case Report. Acta Cytologica, 45, 631-635. https://doi.org/10.1159/000327878

[18] Yang, N., Lu, J., Lu, Y., Guo, J. and Wang, H. (2019) Primary Malignant Melanotic Melanoma and Hypomelanotic Melanoma of the Female Urethra: Case Series and a Review of the Literature in China. Melanoma Research, 29, 59-64. https://doi.org/10.1097/CMR.0000000000000521

[19] Batsakis, J.G. and Suarez, P. (2000) Mucosal Melanomas: A Review. Advances in Anatomic Pathology, 7, 167-180. https://doi.org/10.1097/00125480-200007030-00006

[20] Nakamoto, T., Inoue, Y., Ueki, T., Niimi, N. and Iwasaki, Y. (2007) Primary Amelanotic Malignant Melanoma of the Female Urethra. International Journal of Urology, 14, 153-155. https://doi.org/10.1111/j.1442-2042.2007.01615.x

[21] Katz, E.E., Suzue, K., Wille, M.A., Krausz, T., Rapp, D.E. and Sokoloff, M.H. (2005) Primary Malignant Melanoma of the Urethra. Urology, 65, 389. https://doi.org/10.1016/j.urology.2004.09.002

[22] Bhutani, N., Kajal, P. and Pawar, D. (2017) Primary Malignant Melanoma of the Female Urethra: Report of a Rare Neoplasm of the Urinary Tract. International Journal of Surgery Case Reports, 41, 319-322.

https://doi.org/10.1016/j.ijscr.2017.11.001

[23] Gleason, B.C. and Nascimento, A.F. (2007) HMB-45 and Melan-A Are Useful in the Differential Diagnosis between Granular Cell Tumor and Malignant Melanoma. The American Journal of Dermatopathology, 29, 22-27. https://doi.org/10.1097/01.dad.0000249888.41884.6c

[24] Ohsie, S.J., Sarantopoulos, G.P., Cochran, A.J. and Binder, S.W. (2008) Immunohistochemical Characteristics of Melanoma. Journal of Cutaneous Pathology, 35, 433-444. https://doi.org/10.1111/j.1600-0560.2007.00891.x

[25] Sheffield, M.V., Yee, H., Dorvault, C.C., Weilbaecher, K.N., Eltoum, I.A., Siegal, G.P., Fisher, D.E. and Chhieng, D.C. (2002) Comparison of Five Antibodies as Markers in the Diagnosis of Melanoma in Cytologic Preparations. American Journal of Clinical Pathology, 118, 930-936. https://doi.org/10.1309/EWK9-LUPR-6BC5-1GXV

[26] Amiraian, D., Cernigliaro, J., Zhai, Q.J. and Petrou, S. (2015) Primary Malignant Melanoma of the Female Urethra: A Radiologiic-Pathologic Correlation. Cancer Treatment Communications, 3, 13-16. https://doi.org/10.1016/j.ctrc.2015.01.003

[27] Godechal, Q., Mignion, L., Karroum, O., Magat, J., Danhier, P., Morandini, R., Ghanem, G.E., Leveque, P. and Gallez, B. (2014) Influence of Paramagnetic Melanin on the MRI Contrast in Melanoma: A Combined High-Field (11.7 T) MRI and EPR Study. Contrast Media \& Molecular Imaging, 9, 154-160. https://doi.org/10.1002/cmmi.1554

[28] Zarei, S., Voss, J.S., Jin, L., Jenkins, S.M., Bryce, A.H., Erickson, L.A., Bell, D.A., 
Kipp, B.R. and Flotte, T.J. (2019) Mutational Profile in Vulvar, Vaginal, and Urethral Melanomas: Review of 37 Cases with Focus on Primary Tumor Site. International Journal of Gynecological Pathology. https://doi.org/10.1097/PGP.0000000000000636

[29] van Engen-van Grunsven, A.C., Kusters-Vandevelde, H.V., De Hullu, J., van Duijn, L.M., Rijntjes, J., Bovee, J.V., Groenen, P.J. and Blokx, W.A. (2014) NRAS Mutations Are More Prevalent than KIT Mutations in Melanoma of the Female Urogenital Tract-A Study of 24 Cases from the Netherlands. Gynecologic Oncology, 134, 10-14. https://doi.org/10.1016/j.ygyno.2014.04.056

[30] Abysheva, S.N., Iyevleva, A.G., Efimova, N.V., Mokhina, Y.B., Sabirova, F.A., Ivantsov, A.O., Artemieva, A.S., Togo, A.V., Moiseyenko, V.M., Matsko, D.E. and Imyanitov, E.N. (2011) KIT Mutations in Russian Patients with Mucosal Melanoma. Melanoma Research, 21, 555-559. https://doi.org/10.1097/CMR.0b013e32834bf398

[31] Tacastacas, J.D., Bray, J., Cohen, Y.K., Arbesman, J., Kim, J., Koon, H.B., Honda, K., Cooper, K.D. and Gerstenblith, M.R. (2014) Update on Primary Mucosal Melanoma. Journal of the American Academy of Dermatology, 71, 366-375.

https://doi.org/10.1016/j.jaad.2014.03.031 